\title{
COMPORTAMENTO DE VARIEDADES DE Vigna unguiculata WALP EM RELAÇO AO ATAQUE DE Empoasca kraemeri ROSS \& MOORE, 1957
}

\author{
G.J. MORAES ${ }^{l}$ C.A.V. DE OLIVEIRA ${ }^{1}$
}

\begin{abstract}
The cowpea varieties behavior in relation to the attack of leafhopper, Empoasca kraemeri Ross \& Moore, 1957
\end{abstract}

The cowpea varieties 'Pitiúba', 'Sempre Verde' and 'Vita 3' were tested in Petrolina-Pernambuco, northeastern Brazil, to ob serve their behaviour relation to the attack of leafhopper, Empoas ca kraemeri Ross \& Moore, 1957. The first two are common, local va rieties, whereas the third was recently introduced from Nigeria, where, reportedly, it is tolerant to Empoasca dolichi Paoli. All three varieties presented considerable yield reductions due to the attack of leafhopper. 'Pitiuba' showed the least yield reduction.

\section{INTRODUÇÃO}

A cigarrinha verde, Empoasca kraemeri Ross \& Moore, 1957, è uma das principais pragas do feijão macassar, Vigna unguiculata Walp, no trópico semi-ärido do Brasil. As folhas atacadas apresen tam-se curvadas para baixo e com os bordos amarelados. Quando o ni vel populacional deste inseto è muito elevado, as plantas tornam se raquiticas e tēm a produção grandemente reduzida. Os maiores da nos são causados quando a incidência do inseto se dà no período qué se inicia alguns dias antes da floração e continua até a formação de grãos (MORAES et alii, 1980).

A intensidade dos danos causados pela cigarrinha verde va ria de acordo com a densidade populacional do inseto e com a varie dade de feijão macassar considerada. 0 objetivo deste trabalho foí verificar o comportamento de très variedades de feijãomacassar, soba

Recebido em 25/05/81

${ }^{1}$ CPATSA/EMBRAPA - 56.300 - Petrolina-PE 
ação de diferentes niveis populacionais do inseto, na região do trópico semi-ärido do Brasil. As duas primeiras são variedades 1o cais, largamente cultivadas pelos agricultores, enquanto que a ter ceira foi recentemente introduzida da Nigéria, onde é tida como ré sistente ao ataque da cigarrinha verde, Empoasca dolichi Paoli, do trips Sericothrips occipitalis, do nematóide Meloidogyne incognita (Kafoid \& White) e de diversas doenças da origem füngica, bacteria na e virötica (SINGH et alii, 1975; SINGH, 1977). No Brasil, estāa variedade apresenta-se também resistente a Liriomyza sativae Blan chard (MORAES et alii, 1981).

\section{MATERIAIS E METODOS}

Este trabalho foi conduzido no campo Experimental de Bebe douro, em Petrolina-Pernambuco. Para se poder avaliar o efeito de diferentes niveis populacionais da cigarrinha verde sobre a produ tividade de cada variedade, o experimento foi realizado em três $\overrightarrow{\mathrm{e}}$ pocas, correspondente às seguintes datas de plantio: 23 de abril, 13 de agosto e 2 de novembro de 1980.

A cultura foi conduzida sob condições de irrigação por sul cos, empregando-se o delineamento de blocos ao acaso, com quatro repetições e com dois fatores completamente cruzados, sendo um fa tor referente à proteção da cultura (protegido com inseticida $\bar{e}$ não protegido) e outro, referente a diferentes variedades ('Pitiü ba', 'Sempre Verde' e 'Vita-3'). As parcelas protegidas receberam tratamentos semanais de monocrotofós à razão de $8 \mathrm{~g}$ do p.a./10 $\ell$ de àgua. O espaçamento empregado foi de $1,0 \mathrm{~m} \times 0,50 \mathrm{~m}$, deixando-se duas plantas por cova. A adubação foi feita apenas em fundação, à base de $200 \mathrm{~kg}$ de sulfato de amónio, $300 \mathrm{~kg}$ de superfosfato simples e 50 $\mathrm{kg}$ de cloreto de potássio por ha. A área ütil de cada parcela foi de $12,5 \mathrm{~m}^{2}$, na primeira repetição, e $24,0 \mathrm{~m}^{2}$, nas segunda e terceira repetições.

Para a avaliação do nivel de incidencia da cigarrinha ver de, procedeu-se à contagem semanal do número de ninfas por folíolo. Nesta avaliação, tomaram-se 20 foliolos de cada uma das parcelas não tratadas com inseticida. Estes foliolos foram tomados ao acaso na região intermediäria das plantas.

Procedeu-se também à avaliação dos danos causados pelo in seto às folhas, com base na seguinte escala de notas:

1 - foliolos sem dano;

2 - foliolos levemente curvados;

3 - foliolos medianamente curvados, sem descoloração;

4 - foliolos medianamente curvados, com manchas cloróticas;

5 - foliolos bastante curvados, com manchas cloróticas.

Em cada uma das très épocas, apenas uma avaliação de danos às folhas foi feita, entre o quadragésimo sétimo e o quinquagésimo 
dia após o plantio, tomando-se dez folíolos em cada uma das parce ças não tratadas.

No final do ciclo da cultura, realizaram-se cinco colhei tas, espaçadas de 7 dias. As produtividades apresentadas neste trā balho representam a soma das cinco colheitas.

\section{RESULTADOS, DISCUSSÃO E CONCLUSŌES}

0 Quadro 1 mostra os niveis de incidencia da cigarrinha verde, danos causados às folhas e seu efeito sobre a produtividade. QUADRO 1 - Niveis de incidência de E. kraemeri, danos causados às folhas e efeito do inseto sobre a produtividade de $V$. unguiculata.

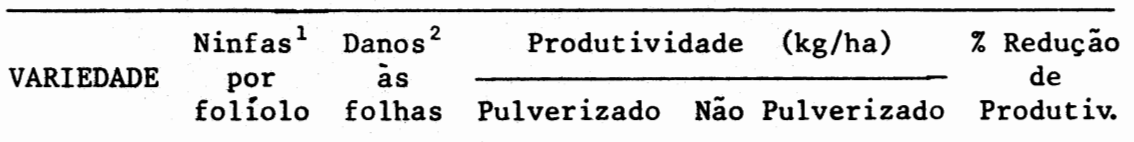

Primeira Epoca (plantio em 23.4.80)

\begin{tabular}{|c|c|c|c|c|c|}
\hline $\begin{array}{l}\text { Pitiüba } \\
\text { S. Verde } \\
\text { Vita-3 }\end{array}$ & $\begin{array}{l}0,24 \\
0,29 \\
0,34\end{array}$ & $\begin{array}{l}2,11 \\
2,54 \\
1,92\end{array}$ & $\begin{array}{l}1847 \\
1641 \\
1995\end{array}$ & $\begin{array}{l}1240 \\
1220 \\
1158\end{array}$ & $\begin{array}{l}33 \\
26 \\
42\end{array}$ \\
\hline \multicolumn{6}{|c|}{ Segunda Época (plantio em 13.8.80) } \\
\hline $\begin{array}{l}\text { Pitiüba } \\
\text { S. Verde } \\
\text { Vita-3 }\end{array}$ & $\begin{array}{l}2,66 \\
2,86 \\
2,09\end{array}$ & $\begin{array}{l}3,48 \\
3,45 \\
2,18\end{array}$ & $\begin{array}{l}2952 \\
2486 \\
2895\end{array}$ & $\begin{array}{l}999 \\
524 \\
816\end{array}$ & $\begin{array}{l}66 \\
75 \\
72\end{array}$ \\
\hline \multicolumn{6}{|c|}{ Terceira Epoca (plantio em 2.11.80) } \\
\hline $\begin{array}{l}\text { Pitiúba } \\
\text { S. Verde } \\
\text { Vita-3 }\end{array}$ & $\begin{array}{l}1,49 \\
1,63 \\
1,45\end{array}$ & $\begin{array}{l}3,98 \\
4,15 \\
2,45\end{array}$ & $\begin{array}{l}2881 \\
1410 \\
1909\end{array}$ & $\begin{array}{r}1520 \\
142 \\
524\end{array}$ & $\begin{array}{l}4 \\
9\end{array}$ \\
\hline
\end{tabular}

1 Média baseada em contagens semanais, realizadas do 209 ao 609 dia após o plantio.

2 Avaliados 50 dias após o plantio, de acordo com uma escala de no tas de 1 a 5 ( 1 =nenhum dano, 5=foliolos bastante curvados, com manchas cloróticas).

A análise conjunta dos dados das três épocas de plantio mos trou diferença significativa (teste F, $5 \%$ de probabilidade) entre os niveis de incidência observados em cada época. Notou-se que os menores niveis de incidencia ocorreram quando o plantio foi reali zado em fins de abril, enquanto que os maiores ocorreram quando $\frac{1}{0}$ plantio foi realizado em meados de agosto. Entretanto, deve-se con 
ANAIS DA S.E.B., 10(2):255-259, 1981

siderar que, quando o plantio foi realizado em meados de agosto, - pico populacional do inseto foi atingido apenas aos 54 dias após - plantio, quando a maioria das plantas nas parcelas não tratadas jà tinham florado. Por outro lado, quando o plantio foi realizado em fins de novembro, o pico populacional foi atingido jä aos 32 di as após o plantio, antes do inicio do florescimento. Não se obser varam diferenças significativas entre as variedades, nem entre as interaçōes época x variedade, com relação a este parâmetro.

Com relação à intensidade dos danos causados à folhas, a anālise conjunta mostrou a existência de diferenças significativas entre as épocas (teste F, $5 \%$ de probabilidade), variedades ( teste $F, 5 \%$ de probabilidade) e entre as interaçöes época $x$ variedade (teste F, 1\% de probabilidade). Os menores danos foram observados na primeira época de plantio (fins de abril). Entretanto, os maio res danos ocorreram no plantio realizado no inicio de novembro, $\bar{e}$ não naquele realizado em meados de agosto, quando o número médio de ninfas por foliolo alcançou os niveis mais altos. Aparentemente, is to se deve ao fato de que até aproximadamente 40 dias apōs o plañ tio, o numero de ninfas em cada foliolo sempre foi maior no plantió realizado no inicio de novembro. A variedade 'Vita-3' foi a que a presentou os menores danos às folhas nas très épocas de plantio. Com exceção da segunda ëpoca de plantio (meados de agosto), quando ocorreram os maiores niveis de incidéncia da cigarrinha verde, a variedade 'Pitiúba' apresentou sempre menor intensidade de danos às folhas que a variedade 'Sempre Verde'.

As três variedades estudadas apresentaram consideräveis re duções de produtividade, nas três épocas de plantio, quando as plan tas não foram tratadas com defensivo. A anälise conjunta dos dados não mostrou diferença significativa entre as reduções de produtivi dade apresentadas por cada uma das variedades. Notou-se porém dife rença significativa (teste $F, 1 \%$ de probabilidade) entre as redu cões de produtividade observadas nas diferentes épocas e intera cões época $x$ variedade (teste $F, 5 \%$ de probabilidade). As menores reduções de produtividade ocorreram quando o plantio foi realizado em fins de abril, correspondendo aos menores niveis de incidencia da cigarrinha verde. Com a decomposição das somas de quadrados de época e das ințerações época $x$ variedade (SILVA, 1977), constatou-se que as variedades comportaram-se diferentemente (teste $\mathrm{F}, 1 \%$ de probabilidade) apenas quando o plantio foi realizado no inicio de novembro. Nesta época, a variedade 'Pitiüba' apresentou menores reduções de produtividade que as variedades 'Sempre Verde' e 'Vita $-3^{\prime}$.

Os resultados obtidos mostram que, sob as condições deste experimento, a variedade 'Vita-3' não apresentou resistência ao a taque da cigarrinha verde, contrariamente ao que foi observado por SINGH et alii (1975) e SINGH (1977) na Nigéria. Deve-se, entretan 
to, considerar que a espécie de cigarrinha verde presente naquele pais $E$. dolichi é diferente daquela existente em Petrolina E. krae meri. Dentre as variedades estudadas, 'Pitiüba' mostrou-se como $\bar{a}$ mais resistente ao ataque da cigarrinha verde.

\section{LITERATURA CITADA}

MORAES, G.J.; MAGALHAES, A.A.; OLIVEIRA, C.A.V. Resistēncia de va riedades de Vigna unguiculata ao ataque de Limiomyza sativae (Dip tera:Agromyzidae). Pesq. Agrop. Brasil., 16(2). no prelo. 1981 MORAES, G.J.; OLIVEIRA, C.A.V.; ALBUQUERQUE, M.M.; SALVIANO, L.M. C.; POSSIDIO, P.L. Efeito da época de infestação de Empoasca kraemeri Ross \& Moore, 1957 (cigarrinha verde do feijoeiro) (Ho moptera:Typhlocibidae) na cultura de Vigna unguiculata Walp ( fe $\bar{i}$ jão macassar). An. Soc. Entomol. Brasil., 9(1):67-74, 1980.

SILVA, J.G.C. A estrutura do delineamento e seu uso na especifica ção do esquema da anālise da variação. Brasília-DF, EMBRAPA-DMQ, $1977,20 \mathrm{p}$.

SINGH, S.R. Cowpea cultivars resistant to insect pests in world germplasm collection. Trop. Grain Legume BulZ., 9:1-7, 1977.

SINGH, S.R.; WILLIAMS, R.J.; RACHIE, K.O.; RAWAL, K.; NANGJU, D. ; WIEN, H.C.; LUSE, R.A. Vita-3 cowpea (G P-3). Trop. Grain Le gume BulZ., 1:18-19, 1975.

\section{RESUMO}

As variedades 'Pitiüba', 'Sempre Verde' e 'Vita-3' foram testadas em Petrolina-Pernambuco para se observar seus comportamen tos em relação ao ataque da cigarrinha verde, Empoasca kraemeri Ross \& Moore, 1957. As duas primeiras são variedades locais, exten sivamente cultivadas, enquanto que a terceira foi recentemente in troduzida da Nigëria, onde é tida como tolerante a Empoasca doli chi Paoli. As três variedades apresentaram consideráveis reduçōes de produção devido ao ataque da cigarrinha verde. A variedade "Pi tiüba" apresentou os menores indices de redução de produção. 